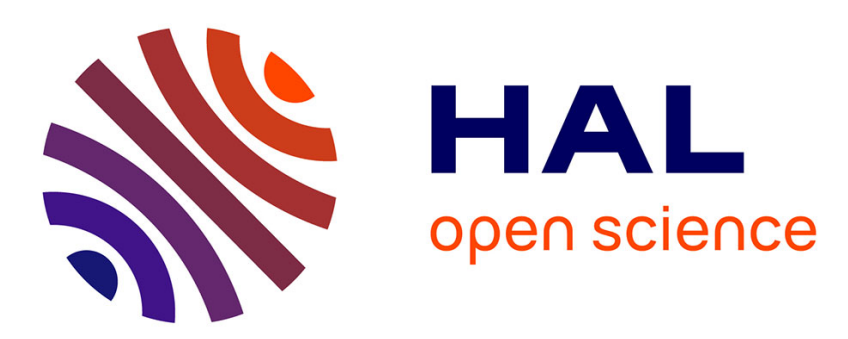

\title{
Non-linearity in photothermal radiometric imaging
}

U. Netzelmann

\section{To cite this version:}

U. Netzelmann. Non-linearity in photothermal radiometric imaging. Journal de Physique IV Proceedings, 1994, 04 (C7), pp.C7-55-C7-58. 10.1051/jp4:1994714 . jpa-00253195

\section{HAL Id: jpa-00253195 https://hal.science/jpa-00253195}

Submitted on 1 Jan 1994

HAL is a multi-disciplinary open access archive for the deposit and dissemination of scientific research documents, whether they are published or not. The documents may come from teaching and research institutions in France or abroad, or from public or private research centers.
L'archive ouverte pluridisciplinaire HAL, est destinée au dépôt et à la diffusion de documents scientifiques de niveau recherche, publiés ou non, émanant des établissements d'enseignement et de recherche français ou étrangers, des laboratoires publics ou privés. 


\title{
Non-linearity in photothermal radiometric imaging
}

\author{
U. Netzelmann \\ Fraunhofer-Institute for Nondestructive Testing (IzfP), University, Bldg. 37, 66123 Saarbrücken, \\ Germany
}

\begin{abstract}
Non-linear effects occurring in photothermal microscopes based on principle of photothermal radiometry are studied as a function of the laser power and of the modulation frequency. For stainless steel, a second harmonic component of up to $11 \%$ of the fundamental amplitude is found. Phase shifts of up to 20 degrees are observed as a function of the modulation frequency. The nonlinearity is mainly due to Stefan-Boltzmann's law. The experimental results are in good agreement with a theoretical model based on the static and oscillating temperature distribution.
\end{abstract}

\section{INTRODUCTION}

Thermal wave microscopy finds new applications in various fields of industrial nondestructive testing. Fast scanning speeds and therefore high signal-to-noise ratios are often required. A common way to improve the signal-to-noise ratio is to increase the laser power applied. When detecting infrared radiation from a periodically heated spot on a surface, Stefan-Boltzmann's law leads to an inherent nonlinearity of the detection, which is normally neglected by assuming small temperature changes. For higher laser powers, this is no longer possible $\left(^{l}\right.$ ), in particular for highly focused photothermal microscopes, where the radial distribution of the local static temperature can have significant effects on the detected photothermal signals.

\section{THEORETICAL MODEL}

A modulated heating beam with a radius $r_{H}$ is assumed to fall onto a half-space with surface absorption and a thermal diffusion length $\mu_{\mathrm{s}}$ (Fig. 1). The heated spot is observed by an infrared detector with a gaussian sensitivity profile with radius $r_{D}$ and with constant sensitivity in the wavelength range $\lambda_{\min }$ to $\lambda_{\max }$. For the material under study, a possible temperature and wavelength dependence of the surface emissivity will be ignored. Then the harmonic part of the detector signal is proportional to:

$S=2 \pi \int_{0}^{\infty} e^{-\left(\frac{r}{r_{D}}\right)^{2}}\left[\int_{\lambda_{\operatorname{mix}}}^{\lambda_{\max }} \frac{\partial R_{b b \lambda}\left(T_{0}+T_{d c}(r)\right)}{\partial T} d \lambda\right\rceil \vartheta(r) r d r \quad$ 
Fig. 1: Sketch of the experimental situation

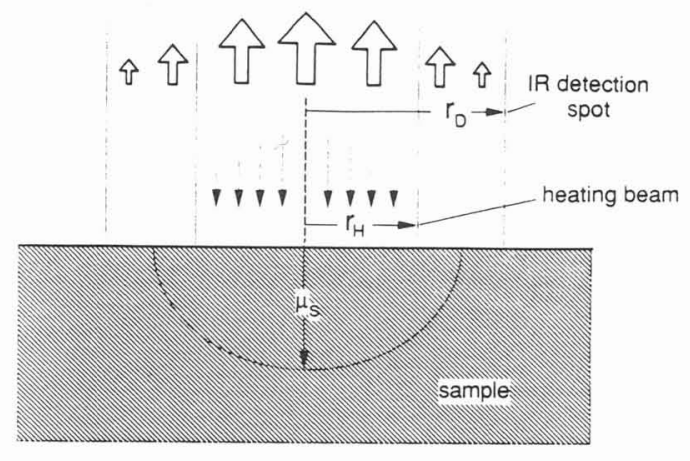

where $R_{b b \lambda}$ is the spectral radiant emittance, $T_{0}$ the ambient temperature, $T_{d c}$ the steady-state temperature increase, $\vartheta$ the temperature oscillation at the sample surface. It is assumed that still $T_{0} \gg T_{d c}|\vartheta|$. For a sample extending into a half-space and using Hankel transforms $\left({ }^{2}\right)$, the radial distribution of the surface temperature due to an absorbed power $P_{0}$ on a material surface with a thermal conductivity $\lambda_{\mathrm{s}}$ can be shown to be given by:

$$
\begin{aligned}
& \mathscr{Q}(r)=\frac{P_{0}}{2 \pi} \int_{0}^{\infty} \frac{1}{\lambda_{s} \sigma_{s}} e^{-\frac{r_{H}^{2} q^{2}}{4}} J_{0}(q r) q d q \quad, \text { where } \quad \sigma_{s}^{2}=q^{2}+i \frac{2}{\mu_{s}^{2}} \\
& T_{d c}(r)=\frac{P_{0}}{2 \sqrt{\pi}} \frac{1}{\lambda_{s} r_{H}} e^{-\frac{r^{2}}{2 r_{H_{H}}^{2}}} I_{0}\left(\frac{r^{2}}{2 r_{H}^{2}}\right) .
\end{aligned}
$$

An analysis of (2) and (3) shows, that for $r_{H} \ll \mu_{S}, T_{d c}(r)$ and $|\vartheta(r)|$ are very close to each other in the illuminated region of the sample. Both amplitude and phase of $\vartheta$ as well as $T_{d c}$ are monotonously decreasing with $\mathrm{r}$. Considering the integral (1), the distribution of the static temperature increase $\mathrm{T}_{\mathrm{dc}}(\mathrm{r})$ emphasises signal contributions from the centre of heating spot, which have a more positive phase than that from more distant regions. This is the mechanism for the power dependent phase shifts we have observed experimentally.

\section{EXPERIMENTS}

In a first experiment, the photothermal signal of a freshly polished, thermally thick plate of stainless steel $\left(\mu_{\mathrm{S}}(1 \mathrm{kHz})=35.4 \mu \mathrm{m}\right)$ was measured by an ALADIN P1 photothermal microscope (Siemens KWU, Offenbach), which uses a Nd-Yag laser as heating source and which is detecting the infrared emission of the sample in the 1 to $5.5 \mu \mathrm{m}$ wavelength range. On a very homogeneous area of the surface, signal amplitude and phase were recorded as a function of the applied laser power for different modulation frequencies (Fig. 2). A non-linear increase of the signal amplitude with laser power is observed, containing a second harmonic amplitude signal of up to $11 \%$. Signal phase is increasing with laser power for more than 20 degrees.

A second experiment was performed in order to distinguish between the non-linear mechanism discussed above and possible other sources of non-linearity, as reported in literature $(3,4,5)$. The photothermal microscope is measuring the signal through the window of a photoacoustic cell $\left(^{6}\right)$ with the sample as the bottom wall (Fig. 3). The cell window consists of $\mathrm{CaF}_{2}$ and is therefore sufficiently transparent for the $1.064 \mu \mathrm{m}$ radiation of the heating beam as well as for the thermal infrared. This arrangement allows to record the photothermal radiometry (PTR) and the photoacoustic (PA) signal of the sample simultaneously and exactly at the same position. 
signal amplitude [a.u.]

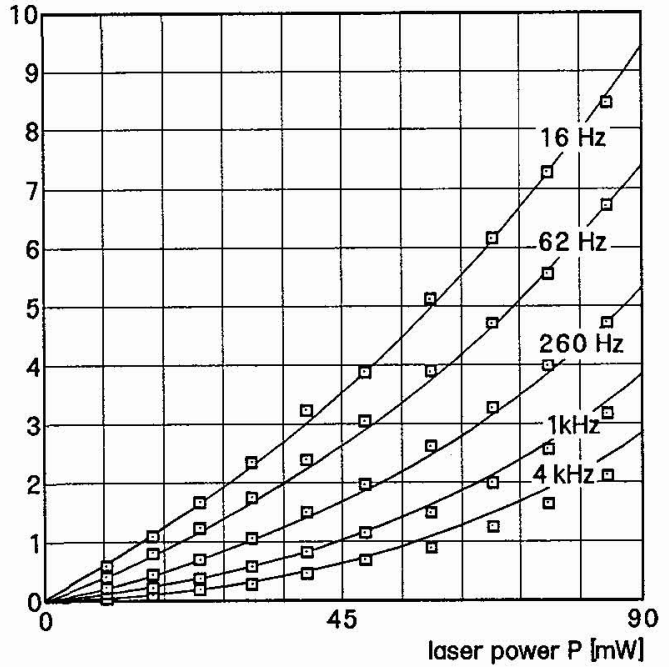

signal phase [deg.]

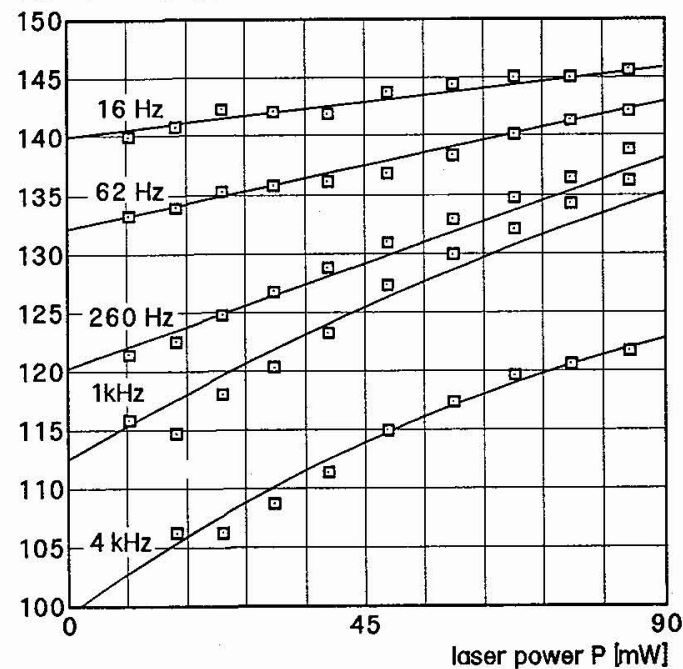

Fig. 2: Theoretical (solid lines) and experimental (squares) photothermal amplitude (left) and phase (right) as a function of the incident laser power for several modulation frequencies

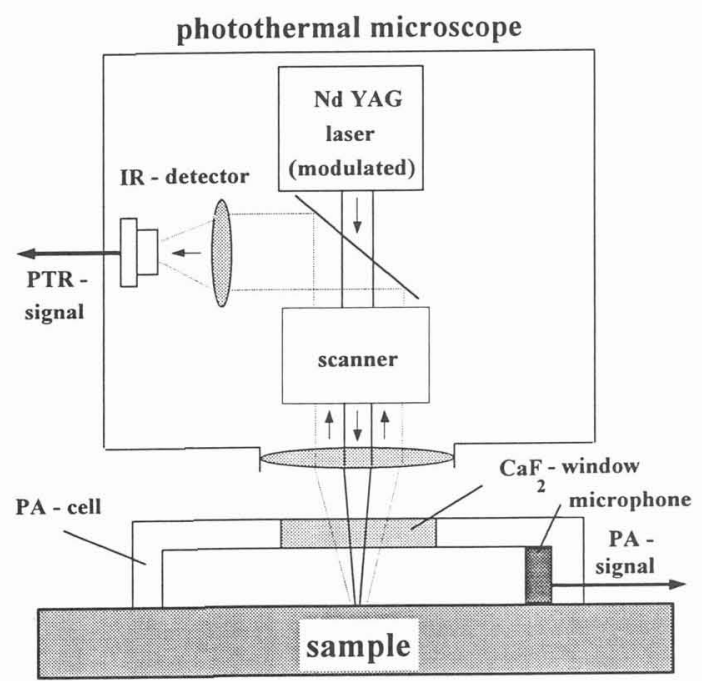

Fig. 3: Arrangement used for simultaneous recording of photothermal radiometry (PTR) and photoacoustic (PA) signals

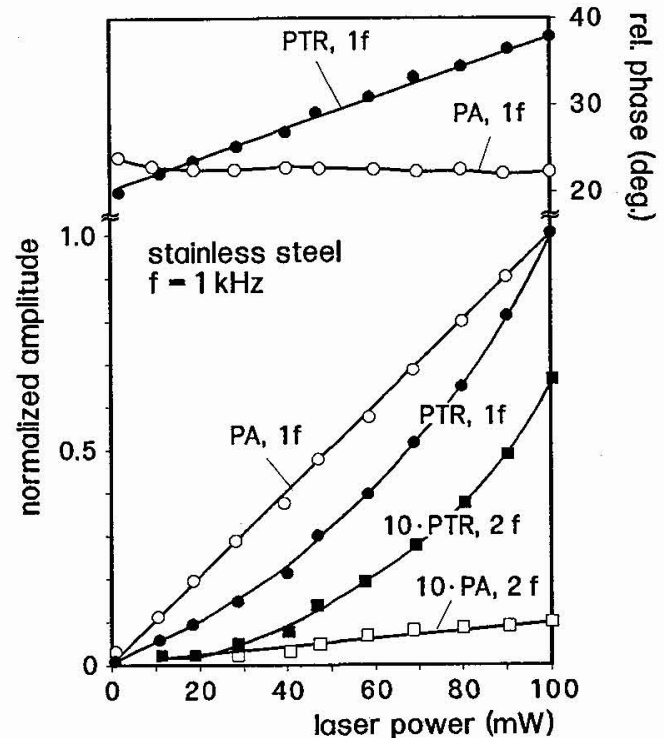

Fig. 4: PTR and PA fundamental (1f) and second harmonic (2f) signals as a function of the laser power. 
Fig. 4 shows the results on the same sample for a modulation frequency of $1 \mathrm{kHz}$ as a function of an applied laser power of up to $100 \mathrm{~mW}$ focused to the surface. The fundamental (1f) as well as the second harmonic (2f) signals have been recorded. All amplitude signals are normalised with respect to the If-PTR signal amplitude at $100 \mathrm{~mW}$. The $2 \mathrm{f}$ signals are multiplied by a factor of 10 for clarity of representation. Where the PTR signal shows a non-linear dependence of the signal amplitude on laser power and power dependent phase shifts, the PA-signal is increasing linearly with frequency and its phase is constant. The $2 \mathrm{f}-$ component is much smaller for the PA-signal than for the PTR signal.

\section{DISCUSSION}

The PA-signal is depending on optical absorptivity and thermal properties of the sample and on the gas properties in the cell. Its linearity as a function of the laser power shows, that none of these properties is source of a notable non-linearity for this particular sample (a small $2 \mathrm{f}$-component of the same relative size as found in the PA-signal can also be detected in the excitation light due to an imperfection of the modulation). The remaining sources of the non-linearity of the PTR-signal are Stefan-Boltzmann's law and a temperature dependent emissivity. In the temperature range considered here, the latter will usually have a smaller influence than the first.

These results justify to compare the experimental data of the first experiment with a theoretical calculation based on the relations (1)-(3). The factor describing the efficiency of the infrared emission (square bracket in (1)) is calculated using $T_{0}=295 \mathrm{~K}$ and $T_{d c}$ from (3), as well as a heating beam radius of $r_{H}=3.5 \mu \mathrm{m}$ and an optical reflectivity of the steel surface of 0.5 . For example, in the case of an absorbed laser power of 10 $\mathrm{mW}$, the emission efficiency in the centre of the beam is nearly a factor of 4 higher than in the outer zones of the heated spot. The integration under consideration of a detection profile of $r_{D}=200 \mu \mathrm{m}$ (determined experimentally) finally gives the solid lines in Fig. 2, which have been fitted to the experimental data by frequency dependent phase offsets and amplitude factors at $P=20 \mathrm{~mW}$ correcting for the unknown overall system response. The agreement with the experimental data is good.

\section{CONCLUSION}

Our experiments show that non-linearity in photothermal radiometric imaging due to Stefan-Boltzmann's law influences not only signal amplitudes but also signal phases. These effects easily occurring when working with highly focused excitation beams must be separated from phase shifts to be used for the analysis of layer thicknesses, defect sizes or thermal resistances.

As a useful consequence of non-linearity we have found in accordance with previous results by mirage detection $\left({ }^{3}\right)$, that the contrast of surface cracks in thermal images is improved.

\section{REFERENCES}

[1] Busse, G., in: Physical Acoustics, Vol.18, Mason, W., and Thurston, R. (eds.)

(Academic Press, San Diego 1988) p. 403

[2] Opsal, J., Rosencwaig, A., and Willenbourg, D., Appl. Optics 22 (1983) 3169

[3] Rajakarunayake, Y. N., and Wickramasinghe H. K., Appl. Phys. Lett. 48 (1986) 218

[4] Wetsel, G. C., and Spicer, J. B., Can. J. Phys. 64 (1986) 1269

[5] Gusev, V., Mandelis, A., and Bleiss, R., Int. J. Thermophys. (in press)

[6] Gissinger, S., Diploma Thesis, (ENSIMEV Valenciennes and IzfP Saarbrücken, 1993) 